\title{
Factors Underpinning Caregiver Burden in Frontotemporal Dementia Differ in Spouses and their Children
}

\author{
Cassandra Kaizik ${ }^{\mathrm{a}}$, Jashelle Caga ${ }^{\mathrm{b}}$, Julieta Camino ${ }^{\mathrm{h}}$, Claire M. O’Connor ${ }^{\mathrm{c}}$, Colleen McKinnon ${ }^{\mathrm{d}}$, \\ Jan R. Oyebode ${ }^{\mathrm{e}}$, Olivier Piguet ${ }^{\mathrm{a}, \mathrm{f}, \mathrm{g}}$, John R. Hodges ${ }^{\mathrm{a}, \mathrm{f}, \mathrm{g}}$ and Eneida Mioshi ${ }^{\mathrm{h}, *}$ \\ ${ }^{a}$ Neuroscience Research Australia, Sydney, Australia \\ ${ }^{\mathrm{b}}$ Sydney Medical School, Brain and Mind Research Institute, University of Sydney, Camperdown, Australia \\ ${ }^{\mathrm{c}}$ Ageing, Work \& Health Research Unit, Faculty of Health Sciences, University of Sydney, Sydney, Australia \\ ${ }^{\mathrm{d}}$ Westmead Hospital, Western Sydney Local Health District, Sydney, Australia \\ ${ }^{\mathrm{e}}$ School of Dementia Studies, University of Bradford, UK \\ ${ }^{\mathrm{f}}$ School of Medical Sciences, University of New South Wales, Sydney, Australia \\ ${ }^{\mathrm{g}}$ ARC Centre of Excellence in Cognition and its Disorders, Sydney, Australia \\ ${ }^{\mathrm{h}}$ Faculty of Medicine and Health Sciences, University of East Anglia, Norwich, UK
}

Accepted 5 December 2016

\begin{abstract}
The objectives of this observational study were to (1) compare spousal and child caregiver burden; (2) compare co-resident and live-out child caregiver burden; and (3) investigate factors influencing spousal and child caregiver burden. Data was collected from 90 caregivers of people with frontotemporal degeneration (FTD) recruited from the Frontotemporal Dementia Research Group (Frontier) at Neuroscience Research, Australia. Of this caregiver group, 43 were spousal caregivers and 47 were child caregivers. Caregiver burden and emotional state were evaluated using the short Zarit Burden Interview and the short version of the Depression, Anxiety and Stress Scale-21. The Social Network Index was applied to ascertain the social network of the caregiver, while the Intimate Bond Measure was used to evaluate the current quality of the relationship between the caregiver and the person with dementia. The Frontotemporal Dementia Rating Scale was used to assess severity of dementia. Spousal and child caregivers experienced similar levels of burden, depression, anxiety, and stress, regardless of disease severity. Co-resident child caregivers had smaller social networks and greater burden than live-out caregivers. Dementia severity was key in spousal caregiver burden, whereas caregiver depression was most important in child caregiver burden. Child and spousal caregivers of individuals with FTD share similar levels of burden, influenced by different factors. Future interventions need to account for these differences.
\end{abstract}

Keywords: Caregiver, carer burden, children, dementia severity, depression, frontotemporal dementia

\section{INTRODUCTION}

Frontotemporal dementia (FTD) affects family caregivers in many dimensions of life, leading to significant levels of burden and stress [1-3]. As a group, FTD caregivers report higher burden than caregivers

\footnotetext{
${ }^{*}$ Correspondence to: Prof. Eneida Mioshi, University of East Anglia, Faculty of Medicine and Health Sciences, School of Health Sciences, The Queen's Building, Norwich Research Park, Norwich, NR4 7TJ, UK. Tel.: +44 1603 593300; E-mail: e.mio shi@uea.ac.uk.
}

of individuals with Alzheimer's disease (AD) $[4,5]$, but close examination reveals that this difference is led by very high levels of burden in behavioral variant FTD caregivers, while caregivers of individuals with primary progressive aphasia (PPA) variants tend to report similar burden levels to those reported by caregivers of individuals with AD. Recently, it has been described that while caregivers of individuals with semantic variant PPA report relatively low burden at the early stages of the disease, this burden increases markedly over the years [6], confirming the 
key importance of disease severity on caregiver and family burden.

Most of the research published to date has focused on the impact of FTD on spouses, who are usually the primary caregivers. Crucially, in the case of FTD, children may still reside at home and will closely experience the changes that occur in their affected parent. In addition to coping with a changing child-parent relationship, they may also be actively involved in providing care for their parent [7]. Children living apart from an affected parent may also play a key role in providing care, particularly when the parent is without a spouse. Research into the impact of the caregiver role on children is finally emerging [8-10], but remains scarce. Much of the relevant work examines the impact of young onset dementia, where symptoms emerge before the age of 65 , and can include a number of diagnostic groups. The impact for children with a parent who has FTD specifically has not been systematically reported to date [11].

In this study, we aimed to investigate (1) whether there is a difference in burden between spouses and children; (2) whether there is a difference in burden between children living at home with the affected parent and children living elsewhere; (3) the role of disease severity in burden for children; and (4) whether factors associated with caregiver burden differ between spouses and children.

\section{METHODS}

\section{Participants}

Data was collected from 90 caregivers of people with FTD, recruited from the Frontotemporal Dementia Research Group (Frontier) in Sydney, Australia between November 2009 and September 2010. Of this caregiver group, 43 were spousal caregivers and 47 were child caregivers. Given the inclusive approach of the study, multiple children from the same family were allowed to participate, and spouses and children from the same family were included. In all, 71 families were involved in this study; 5 families included 2 child caregivers (siblings); 1 family included three children, and 11 families included a spouse and child from the same family.

In this study, a caregiver was defined as an individual providing unpaid care and support for a spouse or parent. FTD was diagnosed according to current criteria for behavioral variant FTD, semantic variant PPA, non-fluent variant PPA [12], cortical basal degeneration [13], or progressive supranuclear palsy [14, 15]. Given the under-investigation of the impact of FTD on children, we chose an all-inclusive approach comprising all clinical variants of FTD.

Data were obtained via an online survey (Survey Monkey) or were retrieved from the Frontier database. Of note, most children answered the online survey. All caregivers and patients consented to the study and ethics approval was obtained from the Human Research Ethics Committees of South Eastern Sydney Local Health District and the University of New South Wales.

\section{Instruments: caregiver related}

\section{Caregiver burden and emotional state}

Caregiver burden was evaluated using the short Zarit Burden Interview (ZBI) [16], which encompasses 12 items and has been widely used in caregiver burden studies. The ZBI is a self-complete tool, and caregivers are asked to rate their feelings in terms of frequency. Responses are measured on a 5-point Likert scale where $0=$ never and $4=$ nearly always and the scores range from ' 0 ' to ' 48 '. High scores denote increased burden, with a score of 17 suggested to indicate clinically significant burden [17].

To assess caregivers' depression, anxiety and stress, the short version of the Depression, Anxiety and Stress Scale-21 (DASS 21) [18] was used. The DASS 21 is a self-report questionnaire that measures the severity of a range of symptoms found in depression, anxiety and stress. Each item is scored from 0 (did not apply to me at all during the previous week) to 3 (applied to me very much or most of the time during the previous week). Existing normative data on the three subscales suggest cut-off scores of 10 and above reflect significant depression, 8 and above indicate significant anxiety, and 15 and above reflect significant stress [19].

\section{Caregiver social network}

To investigate the impact of social networks on caregiver burden, the Social Network Index (SNI) [20] was applied. This tool has been previously used in studies of caregiver burden and stress in FTD [21]. The SNI assesses participation in 12 types of social relationships. These include relationships with a spouse, parents, parents-in-law, children workmates, neighbors, etc. One point is given for each type of relationship for which respondents indicate that they contact persons in that relationship at least 
once every two weeks. Based on earlier results, focus was given to the subscore for "number of high contact roles", that is, the number of people identified (relative, friend, colleague, acquaintance) that the caregiver sees or speaks to at least every two weeks.

\section{Instruments: person with dementia}

\section{Disease severity}

The Frontotemporal Dementia Rating Scale (FTDFRS) was used to ascertain severity of dementia in this study. The FTD-FRS is a well-validated dementia staging tool in FTD [21], based on an interview with a caregiver or relative, and contains 30 questions regarding changes in behavior and function (including shopping, household chores/telephone use, finances, medication administration, meal preparation, eating, self-care, and mobility). The FTD-FRS can identify six stages of severity and defines logit score cut-offs to grade impairment as 'very mild' (>4.12), 'mild' (4.11-1.92), 'moderate' (1.91 to $-0.40)$, 'severe' ( -0.39 to -2.58$)$, 'very severe' $(-2.57$ to -4.99$)$, and 'profound' $(-<4.99)$. Higher scores reflect milder stages.

\section{Change in bond between caregiver and person with dementia}

The current quality of the relationship between the caregiver and the person with dementia was evaluated using the Intimate Bond Measure (IBM) [22]. This measure assesses the relationship from the caregiver's perspective and generates two subscale scores, one which reflects a caring relationship from patient toward the caregiver (IBM Care), and one which reflects a controlling type of relationship from the patient towards the caregiver (IBM Control). The questionnaire contains 24 items which measure this relationship on a scale from 0 (very true) to 3 (not true), and total scores on each subscale range from 0-36. On the IBM Care subscale, higher scores reflect a more positive relationship while on the IBM Control subscale, lower scores denote a more rewarding relationship. Therefore a high Care score and a low Control score can be considered optimal in a relationship [23].

\section{Data analyses}

Data were analyzed using IBM SPSS (Version 20). One-Sample Kolmogorov-Smirnov Tests were used to check for normal distribution of scores within the spousal caregiver group and within the child caregiver group. Log transformations were required for the Depression and Anxiety subscales of the DASS21 and the SNI-High Contact Roles subscale due to non-normal distributions. For the purposes of clinical interpretation, however, the tables report the means and standard deviations. Independent $t$ tests were used to compare spousal caregivers with child caregivers for the different variables. Chi square tests were used for comparisons of categorical variables.

Multiple regression analysis (stepwise method) was used to identify which variables could best predict the variance of burden scores in the spousal caregiver and child caregiver groups; we run each group analyses separately. A stepwise method was preferred given that there is very little evidence in the literature of which factors would explain the variance of caregiver burden in child caregivers in FTD.

\section{RESULTS}

In this first section of the results, we will examine the similarities and differences of aspects of care between child caregivers and spousal caregivers. These will be followed by the comparisons between children living with an affected parent and those living elsewhere.

Ninety caregivers were included in the analyses: of the 47 child caregivers, 39 (83\%) did not live in the same house as the person with FTD, while $8(17 \%)$ did, and the majority ( $81 \%$ ) did not consider themselves the main caregiver of the person with FTD. Of the 43 spousal caregivers, only one did not live with the person with FTD; this person lived in full-time residential care. The age of caregivers, understandably, varied between the spousal caregiver and child caregiver groups $(p<0.001)$ but in both the spousal caregiver and child caregiver groups most caregivers were female.

To control for the influence of dementia severity, the caregiver groups (spousal or child) were compared according to the severity of dementia of person they were caring for, with this subdivided into mild-moderate dementia and severe-profound dementia based on their FTD-FRS score (Table 1). Due to missing dementia severity data, Table 1 only shows $67 / 90$ caregivers. In both severity groups the primary caregivers were more likely to be spouses $(p<0.001$ in mild-moderate group, and $p<0.05$ in severe-profound group). 
Table 1

Comparison of children's and spouses' variables on demographics, carer burden, depression, anxiety, social network, and intimate bond measure - care and control (means and SD). FRS-FTD matched

\begin{tabular}{|c|c|c|c|c|c|c|}
\hline & \multicolumn{3}{|c|}{ Mild-Moderate dementia } & \multicolumn{3}{|c|}{ Severe-Profound dementia } \\
\hline & $\begin{array}{c}\text { Children } \\
(n=15)\end{array}$ & $\begin{array}{l}\text { Spouses } \\
(n=29)\end{array}$ & $\begin{array}{c}\text { Children versus } \\
\text { spouses }\end{array}$ & $\begin{array}{l}\text { Children } \\
(n=16)\end{array}$ & $\begin{array}{l}\text { Spouses } \\
(n=10)\end{array}$ & $\begin{array}{c}\text { Children versus } \\
\text { spouses }\end{array}$ \\
\hline Age (years) & $32.2(9.7)$ & $62.5(11.0)$ & $* *$ & $30.7(10.1)$ & $61.9(9.0)$ & $* *$ \\
\hline Sex, female $(\%)$ & 87 & 73 & n.s & 62.5 & 71 & n.s \\
\hline Main carer $(\%)$ & 26 & 89.7 & $* *$ & 18 & 90 & $*$ \\
\hline Live in the same house $(\%)$ & 26 & 100 & $* *$ & 18 & 90 & $* *$ \\
\hline Zarit Burden Interview (cut-off 17) & $15.3(8.2)$ & $15.5(10.1)$ & n.s. & $23.3(11.1)$ & $27(5.8)$ & n.s. \\
\hline Depression (cut-off 9.5) & $7.3(8.6)$ & $6.8(9.9)$ & n.s. & $14.5(14.0)$ & $11.7(5.9)$ & n.s. \\
\hline Anxiety (cut-off 7) & $5.6(7.2)$ & $5.1(7.0)$ & n.s. & $8.2(10.1)$ & $5.7(5.3)$ & n.s. \\
\hline Stress (cut-off 15) & $6.2(5.1)$ & $6(5.4)$ & n.s. & $9.8(6.2)$ & $10.5(3.2)$ & n.s. \\
\hline Social Network High contact roles & $8.7(7.1)$ & $15.4(4.2)$ & $* *$ & $6.3(5.0)$ & $14.1(7.8)$ & $*$ \\
\hline Intimate Bond Measure Care $(0-36)$ & $14.3(8.1)$ & $24.1(10.8)$ & $*$ & $24.1(8.6)$ & $13(3.5)$ & $*$ \\
\hline Intimate Bond Measure Control $(0-36)$ & $21.9(12.1)$ & $11.6(10.8)$ & * & $30.6(6.2)$ & $8.8(7.0)$ & $* *$ \\
\hline
\end{tabular}

$t$ test: ${ }^{*} p<0.05 ;{ }^{* *} p<0.001$.

\section{Child caregivers versus spousal caregivers}

\section{Caregiver burden and emotional state}

As shown in Table 1, in the mild-moderate dementia severity range the two caregiver groups reported very similar levels of burden $(p=0.94)$, with average scores just below the cut-off for high burden. Similarly, in regards to depression, anxiety, and stress, child and spousal caregivers had comparable scores on all three measures $(p=0.86 ; p=0.84 ; p=0.90$, respectively), with scores below the cut-offs, indicating absence of depression, anxiety, or stress as a group.

The scenario was very different in the severeprofound range, where clinically significant caregiver burden (a score above 17 on the ZBI) was reported by both the spousal and child caregiver groups, with no significant difference between the averages of the two groups $(p=0.255)$ (Table 1; Fig. 1). For depression, the scores for both child caregivers and spousal caregivers were indicative of significant clinical depressive symptoms (Table 1); of note, anxiety was above the cut-off for clinical significance in the child caregiver group only. Stress scores were similar and below cut-off for both spousal and child caregivers.

\section{Caregiver social network}

Significant differences were observed between the social networks of child caregivers and spousal caregivers for both the mild-moderate severity group $(p<0.001)$ and the severe-profound group $(p<0.01)$, with child caregivers having less rich social networks than spouses.

\section{Bond between patient and carer}

The bond between caregiver and the person with dementia was markedly different in both the Care and Control domains overall and also when considering the dementia severity groups separately. Of note, both groups reported scores that reflected a sub-optimal relationship (Table 1).
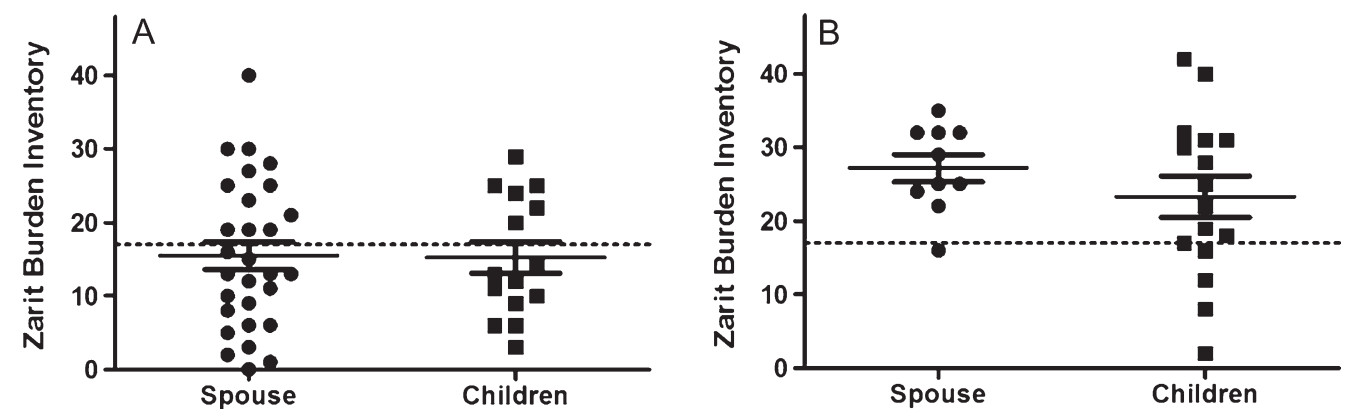

Fig. 1. Distribution of burden scores (ZBI) in child carers and spousal carers, by dementia severity (FTD-FRS). A) Carers of Mild-Moderate FTD patients; B) Carers of Severe-Profound FTD patients ZBI, Zarit Burden Inventory; FTD-FRS, Frontotemporal Dementia Rating Scale; FTD, Frontotemporal Dementia; $\mathbf{\square}$, Children; $\bullet$, Spouse. 
Table 2

Comparison of children living with affected parent versus children living elsewhere, on demographics, carer burden, depression, anxiety, social network and intimate bond measure - care and control (means and SD)

\begin{tabular}{lccc}
\hline & $\begin{array}{c}\text { Children same } \\
\text { household } \\
(n=8)\end{array}$ & $\begin{array}{c}\text { Children different } \\
\text { household } \\
(n=39)\end{array}$ & $\begin{array}{c}\text { Same versus different } \\
\text { household }\end{array}$ \\
\hline Age, years & $24.9(5.7)$ & $35(9.4)$ & $*$ \\
Sex, female (\%) & 37.5 & 77 & $*$ \\
Main carer (\%) & 12.5 & 21 & n.s \\
Zarit Burden (cut-off 17) & $26.6(8.0)$ & $17.3(9.9)$ & $*$ \\
Depression (cut-off 9.5) & $15.3(13.5)$ & $10.4(11.3)$ & n.s. \\
Anxiety (cut-off 7) & $13.3(13.1)$ & $6.4(7.5)$ & n.s. \\
Stress (cut-off 15) & $12(6.3)$ & $7.5(5.7)$ & Trend \\
& & & $p=053$ \\
Social Network: High contact roles & $4.4(1.8)$ & $8.1(6.8)$ & $*$ \\
Intimate Bond Measure: Care & $21.6(10.0)$ & $19.8(9.7)$ & n.s. \\
Intimate Bond Measure: Control & $27(8.8)$ & $26.8(10.1)$ & n.s. \\
\hline
\end{tabular}

${ }^{*} p<0.05$.

In terms of the care domain, in the mild-moderate severity group, both child and spousal caregivers were below the cut-off for an optimal caring relationship with those with dementia. Strikingly, this scenario was significantly worse for the child caregivers $(p<0.01)$ in comparison to spousal caregivers. In the severe-profound severity group the results were reversed, with the spousal caregivers reporting a significantly worse relationship with the person with dementia (less caring) than the child caregivers $(p<0.001)$.

Considering the Control subscale, in the mildmoderate severity group, child caregivers scored significantly higher $(p<0.01)$ than spouses, indicating that they felt a more controlling relationship from the person with dementia; this was also true in the severe-profound group $(p<0.001)$.

\section{Children living with affected parent versus children living elsewhere}

To examine the influence of living arrangements on caregiver burden, the child caregivers were divided into those who lived with the person with dementia $(17 \%)$ and those who did not $(83 \%)$. Child caregivers who were co-resident were significantly younger $(p<0.05)$ than those living away from the parental home (Table 2). Child caregivers living in the same household were significantly $(p<0.05)$ more likely to be male, but there was no significant association $(p=0.570)$ between the living environment and whether the child considered themselves a "primary" caregiver or not. Approximately twelve percent (12.5\%) of those who were co-resident considered themselves the primary caregiver, compared with $21 \%$ of those living separately.

\section{Caregiver burden, emotional state, and social network}

In respect to their emotional state, co-resident child caregivers experienced significantly higher levels of burden $(p<0.01)$ than those living away from the parental home (Table 2). Both groups of child caregivers reported similar high levels of depressive symptoms and stress. Anxiety scores were also similar but the child caregiver group living with the affected parent had a group average above the cut-off for significant anxiety. In regard to social network, child caregivers living at home reported significantly $(p<0.01)$ smaller, or less rich, social networks.

\section{Bond between patient and caregiver}

In regard to quality of the relationship between individuals with dementia and their child caregivers, both child caregiver groups indicated that they perceived a moderately low level of care from the affected parent towards them, but also that their affected parent was very controlling towards them. There was no significant difference in IBM scores between the co-resident group and those living away from the parental home $(p=0.642$ Care; $p=0.967$ Control).

\section{What are the main factors behind caregiver burden in child and spousal caregivers?}

To examine factors underpinning caregiver burden in child caregivers in comparison to spousal 
Table 3

Significant variables contributing to the variance of scores on the $\mathrm{ZBI}(n=70)$

\begin{tabular}{lrcc}
\hline & $\mathrm{B}$ & SE B & $\beta$ \\
\hline SPOUSAL CARERS $^{\mathrm{a}}$ & & & \\
Constant & 18.71 & 1.79 & \\
FTD-FRS & -3.14 & 0.59 & $-0.66^{* * *}$ \\
Carer depression $^{\text {CHILD CARERS }}{ }^{\mathrm{b}}$ & 0.39 & 0.14 & $0.33^{*}$ \\
Constant & & & \\
Carer depression & 12.60 & 1.83 & \\
\hline
\end{tabular}

${ }^{\text {a Note: }} \mathrm{R}^{2}=0.699$ for FRS; $\Delta \mathrm{R}^{2}=0.074$ for Carer depression. ${ }^{*} p<0.05 ;{ }^{* * *} p<0.001{ }^{\mathrm{b}}$ Note: $\mathrm{R}^{2}=0.508$ for Carer depression. ${ }^{* * *} p<0.001$.

caregivers, a multiple regression analysis (stepwise model) was conducted for each caregiver subgroup separately. Given the lack of current evidence on potential predictors of high burden in child caregivers, a backward stepwise model was favored in these analyses. The dependent variable was the Zarit Burden Interview, and independent variables were: caregiver age, caregiver depressive symptoms (DASS-21), caregiver anxiety symptoms (DASS-21), richness of social network (SNI), caring relationship between person with dementia and caregiver (IBM care), controlling relationship from person with dementia to caregiver (IBM control), and disease severity (FTD-FRS).

For the spousal caregivers, the results are presented in Table 3. A significant model emerged from this analysis, which included the FTD-FRS (dementia severity) and caregiver burden. Dementia severity (FTD-FRS scores) explained $70 \%$ of the variance in burden scores for the spouses; depressive symptoms (DASS) explained a further $7 \%$ of variance in $\mathrm{ZBI}$ scores.

For the child caregivers, a significant model also emerged, which was different from the model for the spouses (see Table 3 ). The only variable contributing to the variance in caregiver burden scores was the depressive subscale of the DASS, which explained $51 \%$ of the variance. Dementia severity scores did not enter the model.

\section{DISCUSSION}

This study revealed no differences in perceived burden between spousal and child caregivers of people with FTD, whether dementia was mild to moderate or severe to profound. Critically, the main factors contributing to caregiver burden differed between child caregivers and spousal caregivers.
The severity of dementia was a key factor for spousal caregivers, but depressive symptoms had the greatest impact on caregiver burden for child caregivers.

Clinically significant caregiver burden was reported by both the child caregivers and spousal caregivers of people with FTD who were caring for someone with severe to profound dementia, which confirms previous studies [2, 3, 24]. No study to date, however, has applied quantitative measures of burden with children of individuals with FTD. The child caregivers in this study experienced high levels of burden, even though only $21 \%$ of them identified themselves as the primary caregiver, indicating the broad impact of FTD on the whole family, not just the primary caregiver, and supporting previous findings that younger age is a risk factor for high caregiver burden [25]. The characteristic marked behavioral and personality changes of FTD, and the impact on the family at an earlier stage of the family life cycle are likely to lead to drastic changes in the relationship between affected parent and child, which in turn is likely to affect the child's perceived burden.

There may be specific patterns in the way children react to young onset dementia. Studies suggest that children may be more focused on the needs of both parents than their own, taking on not only practical tasks to assist the family but also emotional support of the primary caregiver and other family members [9]. Children may also worry excessively about the strain of caring on the parent caregiver, and may feel compelled to protect them from any additional strain $[2,9]$.

A large European study comparing caregiver burden in family caregivers of individuals with $\mathrm{AD}$ [25] indicated child caregivers experience a greater level of perceived burden than spousal caregivers, while other studies in AD have indicated greater perceived burden in the live-in spouse [26]. CondeSala's 2014 study [27] examining the trajectory of caregiver burden in $\mathrm{AD}$, found adult children living with an affected parent had experienced the highest burden. Due to the differing typical age of onset in FTD and AD, the child caregivers included in the AD studies are a significantly older group than those included in our study, at a different life stage, with their own children and occasionally grandchildren, limiting the applicability of the AD work in our study population.

Dementia severity seems to be an important predictor of perceived burden for spousal caregivers, but not for child carers [28]. Reasons for this difference could 
be that spousal caregivers tend to be the primary caregivers who take responsibility for daily care through all stages of the disease. This means that the stress associated with daily care has a key influence on their sense of burden. On the other hand, child caregivers may not be as involved in the provision of direct care on a daily basis, so they are less burdened by changes in the level of ability in day-to-day tasks. However, the presence of dementia and its effect on the relationship with the parent nevertheless impacts on the child caregiver's emotional wellbeing irrespective of severity of dementia, as discussed below.

The higher levels of burden in children residing in the same house as the affected parent, compared with live-out children, is likely to be due to a combination of factors. For instance, the co-resident child caregivers were significantly younger and had significantly smaller, less rich, social networks. Age and social network have been demonstrated to be critical influences on reported burden [24]. Child caregivers may be at a time of life when they are still establishing social networks, and those living at home may be reluctant or embarrassed to share their experiences with peers, and so be inhibited in developing and maintaining networks. Finally, it has been reported that younger caregivers feel "disconnected" from health professionals and reluctant to attend medical and other appointments $[9,10]$. In the case of FTD, families have often experienced great difficulty in obtaining a diagnosis, and the frustrations associated with this diagnosis delay may serve as a compounding factor, tainting a child caregivers' enthusiasm to engage with health professionals.

Depressive symptoms seem to be central in the elevated levels of child caregiver burden in FTD. It is possible, however, that these depressive symptoms are a direct reflection of a lengthy process of anticipatory grief, given the gradual and continuous loss experienced, rather than an episode of depression per se, as shown in previous studies involving carers [29]. This differentiation is key because it leads to different approaches of intervention, where the balance of targeting the depressive symptoms or supporting the child caregiver to understand the losses observed has to be carefully weighed. It is likely that an in-depth psychosocial intervention, where the child caregivers can be supported to move through grief [8], emotional detachment and increased maturity [30] could potentially reduce the burden of care, but this remains to be tested. Web-based support (http://www.aftdkidsandteens.org, http://www. lifeandminds.ca/whendementiaisinthehouse) may also address key needs in younger caregivers, but evidence for this is still lacking. Given the complexity of factors in FTD child caregivers, our findings highlight the need to combine dementia, family services, and young onset services support [30] for appropriate and timely care.

This study is not without limitations. Some participants did not complete all assessments, and some caregivers did not consider themselves the primary caregiver, limiting the interpretation of some of the results. Socioeconomic differences between participants were not measured, so results here may not reflect socially disadvantaged groups. Additionally, measures used were not specific for younger populations, given our interest in comparing findings between child caregivers and spousal caregivers. Further data on premorbid caregiver-parent relationships and other characteristics would also have provided valuable information, as would the inclusion of a measure to specifically examine the child-parent bond. Larger sample sizes would be ideal and future studies will address this.

In summary, we identified differences in the burden of care experienced by spousal caregivers and child caregivers, in regard to the factors behind this burden, and further differences between child caregivers living with or apart from their affected parent. The trend for children to stay at home longer, postpone childbearing, and a rise in single-parent families, may result in an increasing future population of child caregivers, particularly those living with an affected parent. These findings are important for the development of service provision, if child caregivers are going to emerge from a caring experience resilient and able to function to their potential.

\section{ACKNOWLEDGMENTS}

The authors are very grateful for the support of all participating patients and family caregivers: spouses and children.

This work was supported in part by funding to ForeFront, a collaborative research group dedicated to the study of frontotemporal dementia and motor neuron disease, from the National Health and Medical Research Council (NHMRC) (APP1037746) and the Australian Research Council (ARC) Centre of Excellence in Cognition and its Disorders (CE11000102). $\mathrm{COC}$ is a recipient of an Alzheimer's Australia Dementia Research Foundation PhD Scholarship. EM is supported by the Alzheimer Association USA 
(NIRP-12-258380). OP is supported by an NHMRC Senior Research Fellowship (APP1103258). JC is supported by a NHMRC Postgraduate Research Scholarship (APP1092891).

Authors' disclosures available online (http://j-alz. com/manuscript-disclosures/160852r1).

\section{REFERENCES}

[1] Mioshi E, Bristow M, Cook R, Hodges JR (2009) Factors underlying caregiver stress in frontotemporal dementia and Alzheimer's disease. Dement Geriatr Cogn Disord 27, 76-81.

[2] Diehl-Schmid J, Schmidt E-M, Nunnemann S, Riedl L, Kurz A, Förstl H, Wagenpfeil S, Cramer B (2013) Caregiver burden and needs in frontotemporal dementia. $J$ Geriatr Psychiatry Neurol 26, 221-229.

[3] Mioshi E, Foxe D, Leslie F, Savage S, Hsieh S, Miller L, Hodges JR, Piguet O (2012) The impact of dementia severity on caregiver burden in frontotemporal dementia and Alzheimer disease. Alzheimer Dis Assoc Disord 27, 68-73.

[4] Riedijk SR, De Vugt ME, Duivenvoorden HJ, Niermeijer MF, Van Swieten JC, Verhey FRJ, Tibben A (2006) Caregiver burden, health-related quality of life and coping in dementia caregivers: A comparison of frontotemporal dementia and Alzheimer's disease. Dement Geriatr Cogn Disord 22, 405-412.

[5] de Vugt ME, Riedijk SR, Aalten P, Tibben A, van Swieten JC, Verhey FRJ (2006) Impact of behavioural problems on spousal caregivers: A comparison between Alzheimer's disease and frontotemporal dementia. Dement Geriatr Cogn Disord 22, 35-41.

[6] Hsieh S, Leyton CE, Caga J, Flanagan E, Kaizik C, O'Connor CM, Kiernan MC, Hodges JR, Piguet O, Mioshi E (2016) The evolution of caregiver burden in frontotemporal dementia with and without amyotrophic lateral sclerosis. J Alzheimers Dis 49, 875-885.

[7] Allen J, Oyebode JR (2009) Having a father with young onset dementia: The impact on well-being of young people. Dementia 8, 455-480.

[8] Hutchinson K, Roberts C, Kurrle S, Daly M (2016) The emotional well-being of young people having a parent with younger onset dementia. Dementia (London) 15, 609-628.

[9] Millenaar JK, van Vliet D, Bakker C, Vernooij-Dassen MJFJ, Koopmans RTCM, Verhey FRJ, de Vugt ME (2014) The experiences and needs of children living with a parent with young onset dementia: Results from the NeedYD study. Int Psychogeriatr 26, 2001-2010.

[10] Barca ML, Thorsen K, Engedal K, Haugen PK, Johannessen A (2014) Nobody asked me how I felt: Experiences of adult children of persons with young-onset dementia. Int Psychogeriatr 26, 1935-1944.

[11] Oyebode JR, Bradley P, Allen JL (2013) Relatives' experiences of frontal-variant frontotemporal dementia. Qual Health Res 23, 156-166.

[12] Gorno-Tempini ML, Dronkers NF, Rankin KP, Ogar JM, Phengrasamy L, Rosen HJ, Johnson JK, Weiner MW, Miller BL (2004) Cognition and anatomy in three variants of primary progressive aphasia. Ann Neurol 55, 335-346.

[13] Armstrong MJ, Litvan I, Lang AE, Bak TH, Bhatia KP, Borroni B, Boxer AL, Dickson DW, Grossman M, Hallett M, Josephs KA, Kertesz A, Lee SE, Miller BL, Reich SG,
Riley DE, Tolosa E, Tröster AI, Vidailhet M, Weiner WJ (2013) Criteria for the diagnosis of corticobasal degeneration. Neurology 80, 496-503.

[14] Rascovsky K, Hodges JR, Knopman D, Mendez MF, Kramer JH, Neuhaus J, van Swieten JC, Seelaar H, Dopper EGP, Onyike CU, Hillis AE, Josephs KA, Boeve BF, Kertesz A, Seeley WW, Rankin KP, Johnson JK, Gorno-Tempini ML, Rosen H, Prioleau-Latham CE, Lee A, Kipps CM, Lillo P, Piguet O, Rohrer JD, Rossor MN, Warren JD, Fox NC, Galasko D, Salmon DP, Black SE, Mesulam M, Weintraub S, Dickerson BC, Diehl-Schmid J, Pasquier F, Deramecourt V, Lebert F, Pijnenburg Y, Chow TW, Manes F, Grafman J, Cappa SF, Freedman M, Grossman M, Miller BL (2011) Sensitivity of revised diagnostic criteria for the behavioural variant of frontotemporal dementia. Brain 134, 2456-2477.

[15] Neary D, Snowden JS, Gustafson L, Passant U, Stuss D, Black S, Freedman M, Kertesz A, Robert PH, Albert M, Boone K, Miller BL, Cummings J, Benson DF (1998) Frontotemporal lobar degeneration. Neurology 51, 1546-1554.

[16] O'Rourke N, Tuokko HA (2003) Psychometric properties of an abridged version of The Zarit Burden Interview within a representative Canadian caregiver sample. Gerontologist 43, 121-127.

[17] Steven HZ, Cheri RA, Mary B (1987) Interventions with care givers of dementia patients: Comparison of two approaches. Psychol Aging 2, 225-232.

[18] Lovibond PF, Lovibond SH (1995) The structure of negative emotional states: Comparison of the Depression Anxiety Stress Scales (DASS) with the Beck Depression and Anxiety Inventories. Behav Res Ther 33, 335-343.

[19] Henry J, Crawford J (2005) The short-form version of the Depression Anxiety Stress Scales (DASS-21): Construct validity and normative data in a large non-clinical sample. Br J Clin Psychol 44, 227-239.

[20] Cohen S, Doyle W, Skoner D, Rabin B, Gwaltney J (1997) Social ties and susceptibility to the common cold. JAMA 277, 1940-1944.

[21] Mioshi E, Hsieh S, Savage S, Hornberger M, Hodges JR (2010) Clinical staging and disease progression in frontotemporal dementia. Neurology 74, 1591-1597.

[22] Wilhelm K, Parker G (1988) The development of a measure of intimate bonds. Psychol Med 18, 225-234.

[23] Brodaty H, Donkin M (2009) Family caregivers of people with dementia. Clin Res 11, 217-228.

[24] Luscombe G, Brodaty H, Freeth S (1998) Younger people with dementia: Diagnostic issues, effects on carers and use of services. Int J Geriatr Psychiatry 13, 323-330.

[25] Reed C, Belger M, Dell'agnello G, Wimo A, Argimon JM, Bruno G, Dodel R, Haro JM, Jones RW, Vellas B (2014) Caregiver burden in Alzheimer's disease: Differential associations in adult-child and spousal caregivers in the GERAS Observational Study. Dement Geriatr Cogn Dis Extra 4, 51-64.

[26] Rinaldi P, Spazzafumo L, Mastriforti R, Mattioli P, Marvardi M, Polidori MC, Cherubini A, Abate G, Bartorelli L, Bonaiuto S, Capurso A, Cucinotta D, Gallucci M, Giordano M, Martorelli M, Masaraki G, Nieddu A, Pettenati C, Putzu P, Tammaro VA, Tomassini PF, Vergani C, Senin U, Mecocci P (2005) Predictors of high level of burden and distress in caregivers of demented patients: Results of an Italian multicenter study. Int J Geriatr Psychiatry 20, 168-174.

[27] Conde-Sala JL, Turró-Garriga O, Calvó-Perxas L, VilaltaFranch J, Lopez-Pousa S, Garre-Olmo J (2014) Three-year trajectories of caregiver burden in Alzheimer's disease. J Alzheimers Dis 42, 623-633. 
[28] Mioshi E, Foxe D, Leslie F, Savage S, Hsieh S, Miller L, Hodges JR, Piguet O (2013) The impact of dementia severity on caregiver burden in frontotemporal dementia and Alzheimer disease. Alzheimer Dis Assoc Disord 27, 68-73.

[29] Marwit SJ, Meuser TM (2005) Development of a short form inventory to assess grief in caregivers of dementia patients. Death Stud 29, 191-205.
[30] Svanberg E, Stott J, Spector A (2010) "Just helping": Children living with a parent with young onset dementia. Aging Ment Health 14, 740-751. 